\title{
THE USES OF AMERICAN SCIENTIFIC POWER
}

\author{
Catherine E. Woteki \\ Dean of Agriculture \\ lowa State University of Science and Technology
}

The world is faced by a perplexing paradox. We have unmatched scientific knowledge that could be used to alleviate hunger, malnutrition, and many of the diseases and dilemmas that afflict humankind, yet nations across the globe are plagued by these and other problems that seemingly defy remedy due, at least in part, to fundamental ignorance of the available solutions.

The editors of the New York Times recently opined (The Uses of American Power, N.Y. Times, March 3, 2002) that "before President Bush decides where next to take the war against terrorism, he and the American people ought to pause for a moment to think about how we intend to behave in this new and awesome role." While we debate what the root causes of terrorism might be, and how and whether the United States should address them while waging war on terrorism, it is worthwhile to consider how we might use American scientific expertise and power to address the underlying causes of terrorism.

Scientific expertise contributes to our domestic security through a myriad of military and homeland defense applications. Science also contributes to global security by addressing fundamental human needs that have been the causes of discontent and war throughout history: hunger, disease, lack of fuel and energy, and economic disparities.

One issue that continues to divide the world is food insecurity - the lack of access to sufficient food to sustain health. As we meet today in Kansas, another important meeting is being held in Rome to follow up on progress since the World Food Summit of 1996 where heads of state and governments from 140 countries pledged to reduce by half the number of undernourished people by the year 2015. At the time the Summit was held, the best estimate of the number of undernourished people worldwide was 840 million. Since 1996, some progress has been made, and estimates are that 815 million people are now undernourished. China has made major improvements in food production and distribution, and most of the drop in the estimates of hungry people is due to China's success. However, trends point to major increases in hunger and malnutrition in the rest of the developing world. Approximately 63 million children are born into poor and undernourished families each year (An appeal by the 15 World Food Prize Laureates on the occasion of the World Food Summit: Five years later, June 2002, Rome).

Nobel laureate Dr. Norman Borlaug and 15 recipients of the World Food Prize believe that meeting basic human needs, such as adequate food, is 
important for global stability. They wrote in a recent op-ed piece: "the world as a whole cannot enjoy durable peace, social stability and economic prosperity while hundreds of millions of people suffer from abject poverty and hunger" (Des Moines Register, June 9, 2002). They also recognize that we have the knowledge to increase significantly food production and food availability worldwide. Rich nations fund $\$ 68$ billion each year of international aid, but only $\$ 11$ billion is for assistance to farmers. The Food and Agriculture Organization of the United Nations is seeking $\$ 24$ billion per year more for agriculture and rural development to help the world's undernourished feed themselves.

What better example could there be of American scientific power benefiting those in need, and in doing so, contributing to global stability? Also, what institutions are better equipped to contribute than the Land Grant Universities? These institutions devoted to teaching, research, and extension are a training ground for students from around the world. Through exchange of faculty and students with partner universities in other countries, the Land Grant Universities disseminate scientific knowledge, and also build an understanding of different cultures. Free exchange of scientific information has been a fundamental principle of these partnerships, and many faculty scientists are concerned about government limits that may be imposed because of fear of disseminating biological technologies to developing countries.

The United States faces a critical decision - whether to focus inward and secure ourselves against those who would do harm through terrorism or to focus outward and use our scientific expertise to help remedy some of the root causes of terrorism. Certainly, we need to strike a balance between the two approaches. To do so, scientists in academia, the private sector, and government will need to actively engage in policy debate on security measures to be placed on research and education. We, in the scientific community, also need to responsibly oppose unrealistic and unnecessary restrictions that could be placed on the free exchange of scientific information. We need to advocate for a balanced program of military, homeland defense, and international research and development while not forsaking our missions. We should also encourage faculty and student involvement internationally, and so continue our tradition of sharing knowledge and building cultural understanding worldwide. We should also advocate for the reform of international organizations such as the Food and Agriculture Organizations and the World Health Organization while we simultaneously support their missions. Achieving greater productivity from important United Nations projects and programs will have long-term benefits for us all. If we decide to engage with the world by sharing our scientific knowledge, we may be able to achieve a Pax Americana that eliminates the inequities that are the foundation for terrorism. 